\title{
Finite element modal analysis and experiment of the compression device of the all-in-one machine of combine harvester and baler
}

\author{
Yaoming $\mathrm{Li}^{1, \text { a }}$, Leihua Zhu ${ }^{2, \mathrm{~b}}$,Zhong Tang ${ }^{3, \mathrm{c}}$ and Lizhang $\mathrm{Xu}{ }^{4, \mathrm{~d}}$ \\ 1,2,3,4 Key Laboratory of Modern Agricultural Equipment and Technology, Ministry of Education and \\ Jiangsu Province, Jiangsu University, Zhenjiang 212013, China \\ aymli@mail.ujs.edu.cn, ${ }^{b}$ 570742007@qq.com, ${ }^{c}$ tangweizhong0427@163.com, ${ }^{d}$ justxlz@126.com
}

Keywords: all-in-one machine of combine harvester and baler; modal test; compression device; modal analysis

Abstract: In order to reduce resonance of all-in-one machine of combine harvester and baler in normal operation, using 3D software of the compression device for parametric modeling, finite element simulation of compression device by ANSYS-Workbench software, calculating the first fourth order modal frequency and formation of compression device, and using modal analysis and modal test to the compression device. Test results show that the finite element simulation and modal test results basically are consistent. By analyzing the external excitation frequency, the first modal frequency of the compression device is similar to the excitation frequency of the vibration sieve, and the form of motion is a reciprocating motion, and the resonance phenomenon is easy to occur. The second modal frequency of the compression device is in the range of excitation frequency of Threshing cylinder, and the resonance phenomenon is obvious when the whole machine is in normal work.

\section{Introduction}

All-in-one machine of combine harvester and baler as a large and complex agricultural machinery, can complete the rice and wheat stalk cutting and threshing, straw bale and other operations, to ensure the normal work of the combine efficiency, at the same time, also realize the straight bale function of rice and wheat straw [1,3], it also can simplify the operation process and reduce the cost of harvesting. However, there are many working parts and transmission parts of the all-in-one machine of combine harvester and baler, during the operation, a lot of noise and vibration will be generated, which will seriously affect the working efficiency of the whole machine. Compression device as the main structure of the all-in-one machine of combine harvester and baler straw conveying and compressing, In the process of harvesting and bundling, mainly affected by the engine, cutter, vibrating reciprocating working parts and the cutting table auger, threshing cylinder, fan, straw feeding shifting fork and rotary moving parts of the external excitation, The whole machine vibration is larger in the range of lower than $100 \mathrm{~Hz}[4,5]$. At the time of the field work, when the external excitation frequency is close to one order frequency of the compression device, the squeezing device will appear resonance, which may lead to the vibration of the whole combined harvester. The dynamic stress caused by the resonance can seriously affect the working performance, life, reliability and comfort of the all-in-one machine of combine harvester and baler, so it is necessary to study the vibration of the compression device [6].

In this paper all-in-one machine of combine harvester and baler compression device structure and working principle is analyzed, and using 3D software Solidworks for the compression device to parametric modeling, modal simulation by using the modal simulation module of ANSYS-Workbench, and solving modal parameters, verified by modal test. By comparing the modal natural frequency and the external excitation frequency, the theoretical reference is provided for the structure design and optimization of the compression device. 


\section{Finite element model establishment and analysis of the compression device Section Headings}

Structure and finite element model of compression device. The core part of the compression packing device of the all-in-one machine of combine harvester and baler is the centering type crank slider mechanism. Its working principle is: The input shaft of the crank will transmit power to the crank, the crank is driven by the connecting rod to make the compression block to make the reciprocating linear motion along the harvester forward direction and the straw is bale compressed in the compression box. The strength, stiffness and dynamic characteristics of the compression device directly influence the quality of the compression bale, the structure of the compression device is shown in figure 1.

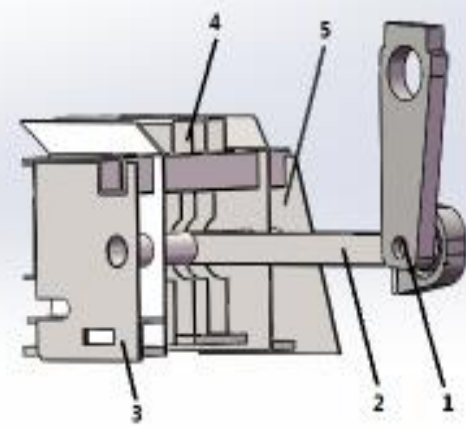

Fig.1 Structure diagram of compression device

1. Crank 2. Connect rod 3. Compression device left side plate 4. Compression device middle plate 5. Compression device right side plate

Select the compression device of 4L-4.0 all-in-one machine of combine harvester and baler as the research object, the whole structure length $877 \mathrm{~mm}$, width $420 \mathrm{~mm}$, high $507 \mathrm{~mm}$, mainly composed of thin-walled plate, angle steel, square steel and round tube rigid connection by welding. In view of the complexity of the structure of the compression device and the rationality of the modeling process, selection of parametric modeling can not only to avoid duplication, but also to shorten the design cycle[7,8].Therefore, this paper uses the 3D modeling software Solidworks to establish the geometry model of the compression device to realize the parameterization of the geometry modeling. In order to improve the efficiency of the simulation, in the process of modeling, simplify the structure which has little influence on the simulation and analysis results[9,10]:

1) The influence of the changes in the physical and chemical properties of welding material on the structure of the compression device is not considered;

2) Remove fine structure which Diameter is smaller than the mesh size of the fillet, small holes that It has little effect on the quality of the model;

3 ) Ignore the welding flange which effect on compressive strength and stiffness of compression mechanism is small;

4) All process holes are ignored.

The basic idea of the finite element simulation is to split the complex structure into a number of simple shape elements, analysis of the overall structure is realized by using the element node variables to carry out the unit internal variable interpolation, the discrete and finite element set will replace the original elastic continuum. Therefore, before the modal calculation, the simplified compression device is divided into a dispersion of a finite element.

In the finite element mesh of the compression device, the material properties of the parts are added, the model material is defined as Q235 structural steel, the elastic modulus is $210 \mathrm{GPa}$, the density is $7800 \mathrm{~kg} / \mathrm{m}^{3}$, and the Poisson's ratio is 0.3 .According to the structure of the compression device, in order to ensure the accuracy and reduce computation time, using 3 dimensional 8 node soild 45 as the basic unit for the implementation of solid compression device non uniform, mesh was divided into 
21620 units, 86639 nodes, through the compression device after meshing finite element model as shown in figure 2.

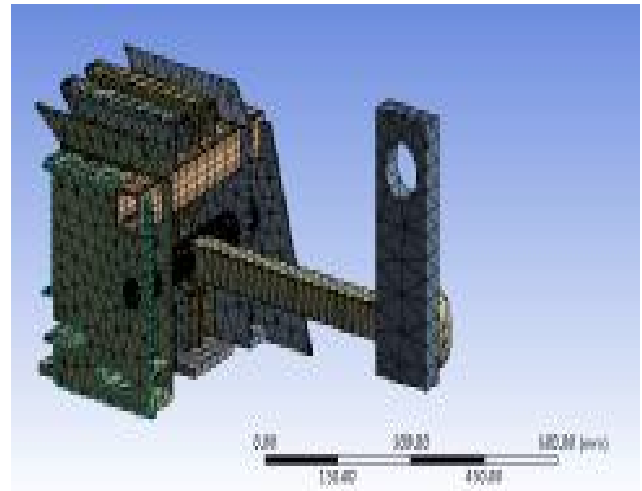

Fig.2 Finite element model of compression device

Modal analysis theory. The modal analysis is used to transform the physical coordinates of the differential equations of the linear system into the modal coordinates, in order to obtain the modal parameters of the system, the equations are decoupled into a set of independent equations, which are described by modal coordinates and modal parameters[11,15].

The structure and material properties of the compression device determine the rigidity characteristics of the system, therefore, it can be described as a multi degree of freedom system without damping and free vibration, its kinetic equation is:

$$
[\mathrm{M}][\mathrm{x}]+[\mathrm{K}][\mathrm{x}\}=\{\mathrm{O}\}
$$

(1) In the formula, the $[\mathrm{M}]$ is the system mass matrix, $[\mathrm{K}]$ is the system stiffness matrix, and the $\mathrm{X}$ is the system node displacement.

The modal analysis theory shows that the free vibration of any elastomeric can be decomposed into the superposition of a series of harmonic vibration; simple harmonic motion equation of the structure can be expressed as:

$$
\mathrm{x}=\mathrm{X} \sin \left(\omega_{\mathrm{n}}+\varphi\right)
$$

(2)In the formula, the $\mathrm{X}$ is the node amplitude, $\mathrm{mm}$; is the natural frequency, $\mathrm{Hz}$; and the is the phase angle $\left({ }^{\circ}\right)$.

Put the formula (2) into the formula (1):

$$
\left([\mathrm{K}]-\omega_{\mathrm{n}}^{2}[\mathrm{M}]\right)\{\mathrm{x}\}=\{0\}
$$

When the system has free vibration, there must be a displacement node, the formula (3) must have a non - zero solution:

$$
\left|K-\omega_{n}^{2} M\right|=0
$$

From formula (1) to formula (4) the system stiffness matrix and the mass matrix are determined by the inherent properties of the system quality and geometric structure, by setting the corresponding frequency, the corresponding equations can be solved (4).If the system has the $n$ degree of freedom, the formula (4) is about the $\omega \_n \wedge 2 n$ sub algebraic equation, which can solve the neaten value and characteristic vector, which is the natural frequency and the structural vibration type of the system.

Modal analysis of compression device. When the all-in-one machine of combine harvester and baler works in the field, The input shaft of the crank will transmit power to the crank, the rotating crank is driven by the connecting rod to do reciprocating linear motion, Therefore, it should be based on the actual situation of the compression device to do modal analysis, after the finite element model 
of the compression device is completed, the displacement constraint is applied to the compression device, and the contact is added at the joint of the crank and the connecting rod. The modal analysis theory shows that the effect of the dynamic characteristics of low order formation compression device structure is larger. Therefore, the finite element analysis of the compression mechanism calculation, only the first four order modal frequency and formation analysis. First fourth order of natural frequencies and vibration mode shapes of compression device as shown in figure 3.

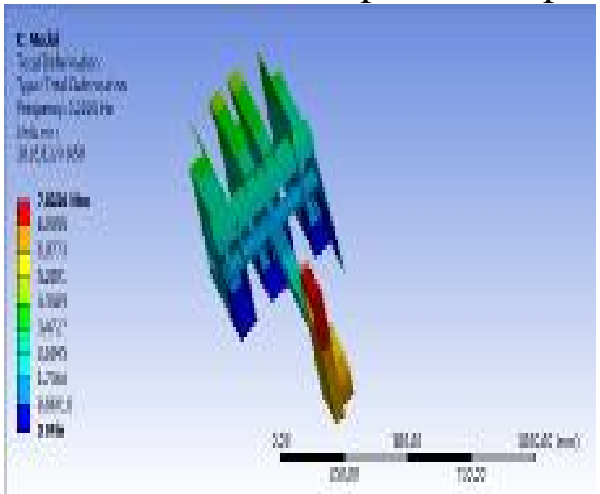

a. 1 st order mode $(3.20 \mathrm{~Hz})$

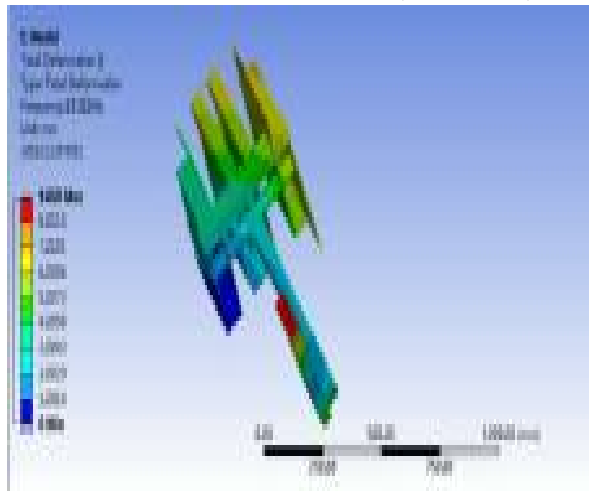

c. 3 st order mode $(29.82 \mathrm{~Hz})$

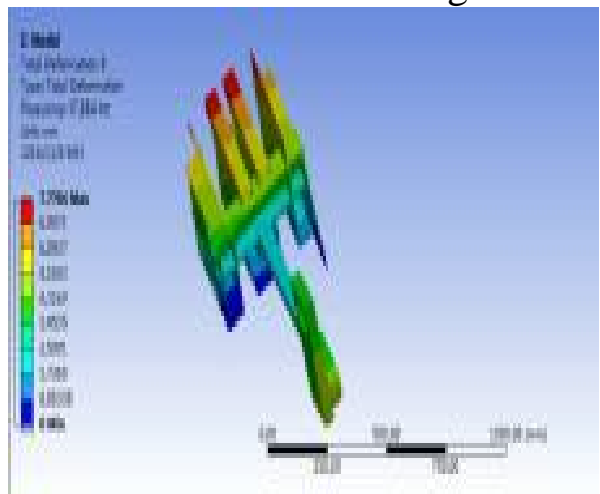

b. 2 st order mode $(17.26 \mathrm{~Hz})$

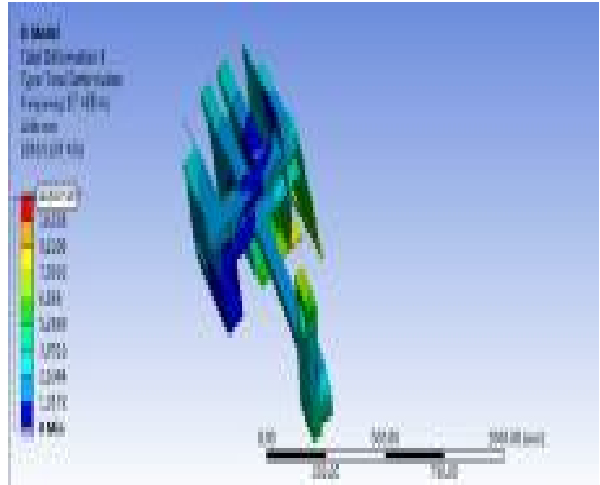

d. 4 st order mode $(57.46 \mathrm{~Hz})$

Fig.3First fourth order of natural frequencies and vibration mode shapes of compression device Modal test of compression device

Test system and test process. After the modal analysis is carried out on the compression device, it is proved that the calculation result is the key step to analyze the compression device through the modal test. The modal test is dynamic testing system based on external excitation and response, it is a test method to determine the modal parameters of the system through the response data of excitation and output system of the input signal processing and parameter identification, because the method can obtain the inherent characteristics of the structural vibration, it is also an important index to judge the accuracy of the finite element simulation[16,17].In the modal test, usually external excitation causes the structure to generate forced vibration, and the modal parameters of the structure can be obtained through the analysis and processing of the signals collected by the forced vibration. Modal testing system mainly consists of three parts: external excitation, data acquisition system, modal analysis and processing system, the basic principle diagram of the modal test is shown in figure 4. 


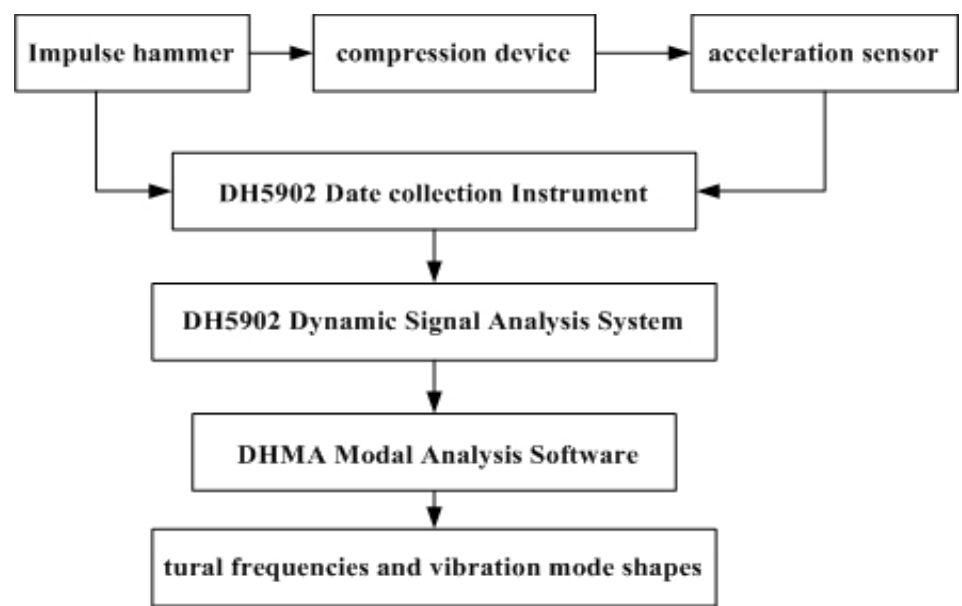

Fig.4 Basic principle diagram of modal test

Test apparatus and method. The test equipment is composed of 4 parts, including the impulse hammer, the three direction acceleration sensor, the data collection instrument, the DH5902 dynamic signal analysis system and the DHMA modal analysis software, etc., as shown in figure 5.

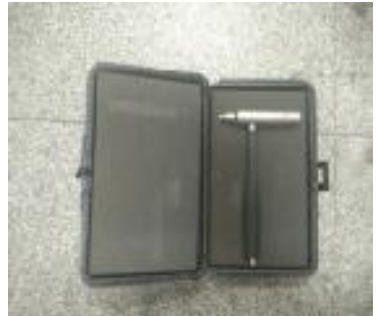

(a) Impulse hammer

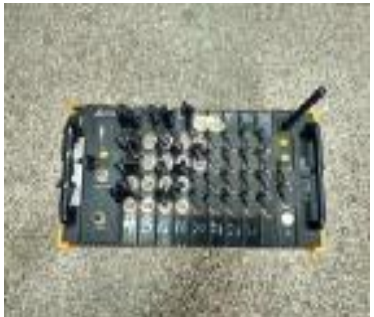

(b) data collection instrument

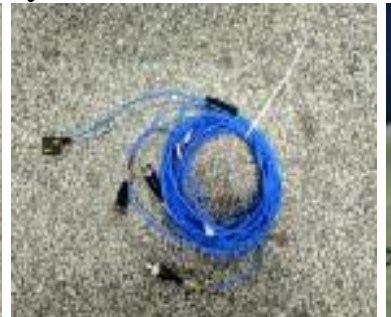

(c) Acceleration sensor

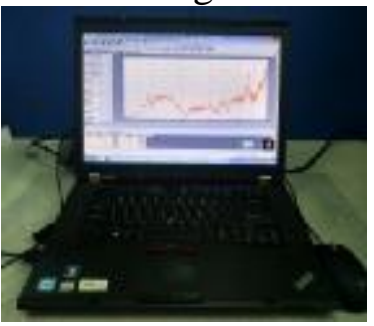

(d)Modal analysis software

Fig.5Modal test equipment of compression device

Signal data acquisition system include the Donghua testing company DH5902 data collection instrument and DH5902 signal analysis processing software, The collection instrument provides 32 digital or analog collection channels, the bandwidth of $100 \mathrm{KHz}$. The distortion is less than $0.5 \%$.Data is stored in a mobile computer via a wireless wifi transmitter or a wired network. Three direction acceleration sensor form American piezoelectric (PCB) 356A16 type sensor, Modal test main equipment technical parameter table as shown in table 1.

Table 1 Modal test main equipment technical parameter table

\begin{tabular}{|c|c|c|}
\hline No. & Device name & Performance index \\
\hline 1 & $\begin{array}{c}\text { Dynamic signal } \\
\text { acquisition } \\
\text { instrument }\end{array}$ & $\begin{array}{l}32 \text { channels, AD resolution } 16 \text { [bit], } \\
\text { bandwidth } 100[\mathrm{KHz}] \text {, distortion }<0.5 \%\end{array}$ \\
\hline 2 & $\begin{array}{l}\text { Dynamic signal } \\
\text { processing } \\
\text { software }\end{array}$ & $\begin{array}{l}\text { DH5902 special dynamic signal analysis } \\
\text { and processing software }\end{array}$ \\
\hline 3 & $\begin{array}{l}\text { Acceleration } \\
\text { sensor }\end{array}$ & $\begin{array}{l}\text { Range } \pm 500\left[\mathrm{~m} / \mathrm{s}^{2}\right] \text {, frequency } \\
\text { response } 0.3-6[\mathrm{KHz}], \text { sensitivity } 10\left[\mathrm{mv} \cdot \mathrm{ms}^{-2}\right]\end{array}$ \\
\hline
\end{tabular}

Test process: according to the existing test conditions, it is difficult to construct the free boundary condition of the structure with the method of elastic rope suspension. Therefore, this experiment uses the rubber bottom of the way, as far as possible to weaken the rigid constraints of the ground on the system, in order to reduce the influence of boundary effect on the modal test[14]. The measuring point is selected in advance on the compression device, and the measuring point is wiped clean, and the three direction acceleration sensor is absorbed at the measuring point. Accurately connect the three direction acceleration sensor, the dynamic model collection instrument, the dynamic signal analysis 
and processing software. This experiment adopts single point excitation and multi-point measured response data method, In the compression device, the position of the large stiffness is selected as the exciting point. When the test is used, the exciting point is struck by the impulse hammer to ensure that the measurement points are fully received to the excitation signal, this moment, the measuring point of the compression device receives the external excitation signal, and the three direction acceleration sensor arranged at the measuring point transmits the system response signal to the data acquisition system. Finally, the collected vibration signals of all measured points are introduced into the DHMA modal analysis software for post processing, and can get the modal parameters of compression device natural frequencies and formation, as shown in figure 6.

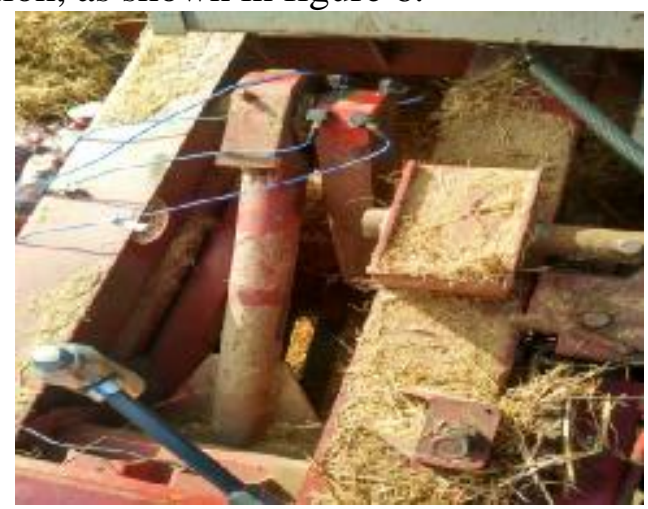

Fig. 6 Test site

Arrangement of measuring points. The measured modal test information requires a possible high signal-to-noise ratio, therefore, the arrangement principle of the measuring point is the external force point, important response point, the point of the cross link of the component or the structure, the whole shape of the compression device can be displayed by the connecting line of the measuring point [18-19] .In the modal test, the model structure is shown in figure 7, a total of 88 nodes, in the position of the node in the corresponding structure diagram, 88 measuring points are arranged in the modal test. It can well define the structure of the compression device.

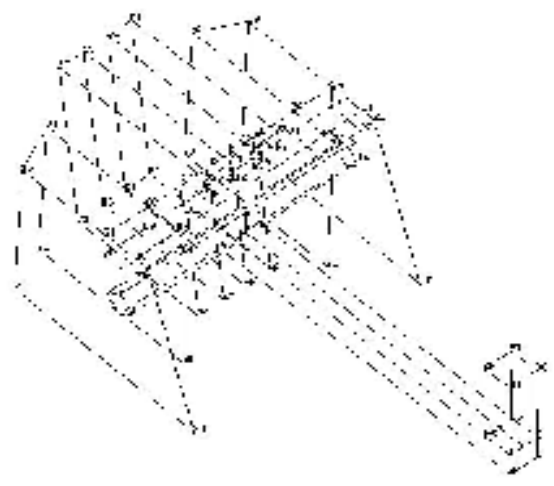

Fig.7 Structure model of modal test

Test results and analysis. The data of frequency response function collected by the dynamic signal acquisition instrument is imported into the DHMA modal analysis software for parameter identification, after data input, peak search, parameter calculation, steady-state diagram check, and finally get the first fourth order modal frequency and formation of compression device, as shown in figure 8.Through the DHMA modal analysis modal software criterion (MAC) to verify the analysis results, as shown in figure 9,It can be seen that the correlation between the modal frequency is 1 , which shows that the results are valid. 


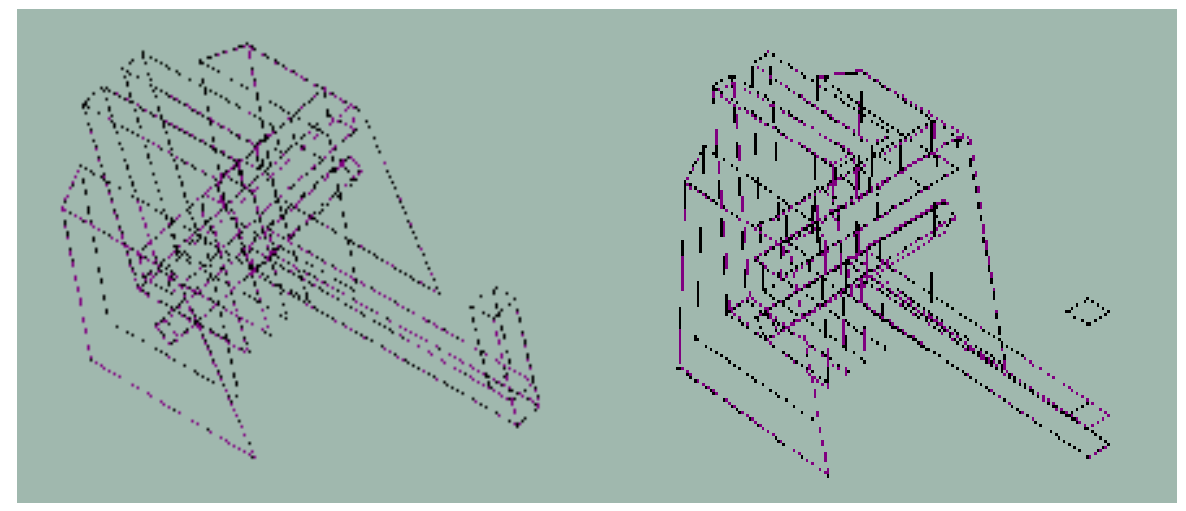

a. 1st order model mode

b. 2 st order model mode

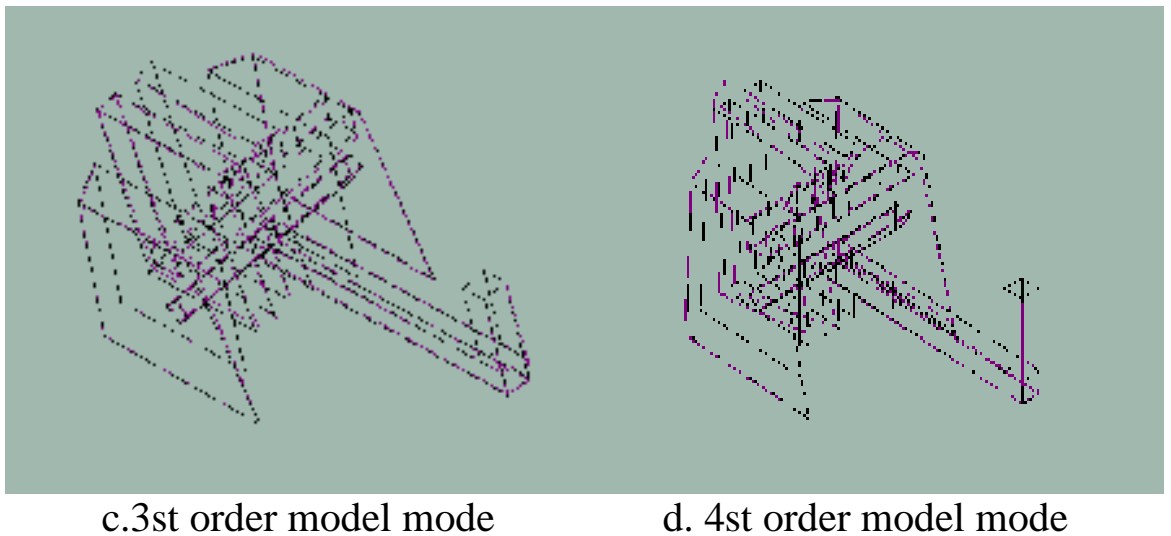

Fig.8 Natural frequencies and vibration mode shapes of testing modal

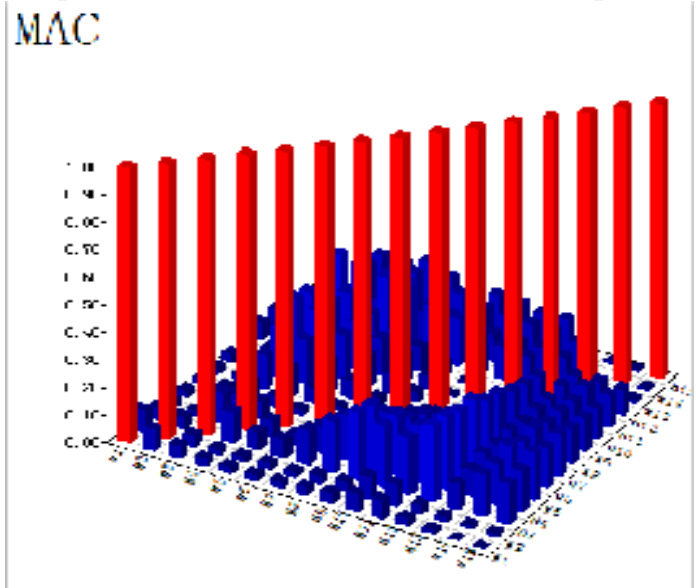

Fig.9 Mode decision histogram

Comparison of finite element simulation results and modal test results. The results of finite element simulation and modal test are compared and analyzed, and the results are shown in table 2 .

Table 2 Comparison of finite element simulation results and modal test results

\begin{tabular}{|c|c|c|c|c|c|}
\hline \multirow[b]{2}{*}{ Order } & \multicolumn{2}{|c|}{ Calculation modal } & \multicolumn{2}{|r|}{ Testing modal } & \multirow{2}{*}{$\begin{array}{c}\text { Frequenc } \\
\text { y error } \\
1 \%\end{array}$} \\
\hline & frequency & $\begin{array}{l}\text { mode of } \\
\text { vibration }\end{array}$ & frequency & $\begin{array}{l}\text { mode of } \\
\text { vibration }\end{array}$ & \\
\hline 1 & $3.20[\mathrm{~Hz}]$ & $\begin{array}{l}\text { Crank and } \\
\text { connecting } \\
\text { rod bending } \\
\text { Crank and } \\
\text { connecting } \\
\text { rod bending }\end{array}$ & $3.34[\mathrm{~Hz}]$ & $\begin{array}{c}\text { Crank and } \\
\text { connecting } \\
\text { rod bending } \\
\text { Crank and } \\
\text { connecting } \\
\text { rod bending }\end{array}$ & $-4.2 \%$ \\
\hline 2 & $17.26[\mathrm{~Hz}]$ & Middle plate & $18.29[\mathrm{~Hz}]$ & Middle plate & $-5.6 \%$ \\
\hline
\end{tabular}




\begin{tabular}{|c|c|c|c|c|c|}
\hline & & $\begin{array}{c}\text { bending } \\
\text { deformation }\end{array}$ & & $\begin{array}{l}\text { front end } \\
\text { bending }\end{array}$ & \\
\hline 3 & $29.82[\mathrm{~Hz}]$ & $\begin{array}{l}\text { Crank bend } \\
\text { Middle plate } \\
\text { bending } \\
\text { Left side } \\
\text { plate bending }\end{array}$ & $29.41[\mathrm{~Hz}]$ & $\begin{array}{l}\text { Crank bend } \\
\text { Middle plate } \\
\text { bending } \\
\text { Left side } \\
\text { plate bending }\end{array}$ & $1.4 \%$ \\
\hline 4 & $57.46[\mathrm{~Hz}]$ & $\begin{array}{l}\text { Middle plate } \\
\text { bending } \\
\text { deformation } \\
\text { Left plate } \\
\text { bending } \\
\text { deformation }\end{array}$ & $58.55[\mathrm{~Hz}]$ & $\begin{array}{l}\text { Middle plate } \\
\text { bending } \\
\text { deformation } \\
\text { Left plate } \\
\text { bending } \\
\text { deformation }\end{array}$ & $-1.9 \%$ \\
\hline
\end{tabular}

It can be seen that the finite element modal simulation results are basically in agreement with the experimental results. The maximum error occurred in the second order and the maximum frequency error is $5.6 \%$, the order of formation change is consistent; The error of finite element modal analysis and modal test results are mainly derived from the finite element modal simulation analysis is in the free state of the compression device, but in the Modal test, the compression device at the bottom of the compression mechanism at the bottom of the constraint.

\section{Excitation frequency analysis}

The external excitation of the all-in-one machine of combine harvester and baler mainly comes from the engine, cutter, vibrating reciprocating working parts and the cutting table auger, threshing cylinder, fan, straw feeding shifting fork and rotary moving parts of the external excitation. Through the analysis of the external excitation of the all-in-one machine of combine harvester and baler, the natural frequency of each order of the compression device can avoid the external excitation frequency, thus effectively avoid the resonance [20,21]. The external incentive analysis of the all-in-one machine of combine harvester and baler is as follows:

1) The frequency of road excitation is mainly determined by the road conditions, the exciting frequency of the common asphalt pavement, the rural land road and the field to the all-in-one machine of combine harvester and baler is generally lower than that of the $3 \mathrm{~Hz}[22]$.

2) When the all-in-one machine of combine harvester and baler works in the field, the engine speed is usually in the $2000-2500 \mathrm{r} / \mathrm{min}$, the engine exciting frequency is $76.6 \mathrm{~Hz}-83.4 \mathrm{~Hz}$, in the engine idle speed, the engine speed is $1050 \mathrm{r} / \mathrm{min}$, at this time the engine exciting frequency is $5 \mathrm{~Hz}$.

3 ) The exciting frequency of the cutter is generated by the reciprocating motion of the cutter, the measured ring cutting mechanism for cutting table input shaft speed is $439 \mathrm{r} / \mathrm{min}$, the cutter exciting frequency is $7.32 \mathrm{~Hz}$.

4) When the all-in-one machine of combine harvester and baler works in the field, the threshing cylinder speed is $750-1100 \mathrm{r} / \mathrm{min}$, the excitation frequency is $12.5 \mathrm{~Hz}-18.3 \mathrm{~Hz}$.

5) The excitation frequency of the vibration sieve is generated by the reciprocating motion of the vibration sieve, the rotating speed of the vibration sieve is $400 \mathrm{r} / \mathrm{min}$, and the excitation frequency is $6.67 \mathrm{~Hz}[23]$.

6) Cutting table auger in the all-in-one machine of combine harvester and baler work to do rotary movement, its rotational speed is $3.07 \mathrm{~Hz}$. The exciting frequency is $184 \mathrm{r} / \mathrm{min}$.

7) The excitation frequency of the fan is caused by the rotation of the fan, and its normal working speed is $1300 \mathrm{r} / \mathrm{min}$, and the excitation frequency is $21.67 \mathrm{~Hz}$.

8) The rotation speed of the straw feeding fork is $93 \mathrm{r} / \mathrm{min}$, and the excitation frequency is $1.55 \mathrm{~Hz}$.

Comparing with the theoretical calculation frequency of the external excitation frequency and the compression device, the first order frequency of the compression device is $3.20 \mathrm{~Hz}$, which is in the range of the low order frequency of the road excitation, the cutting table and the vibration sieve. As the vibration sieve and the compression device in the form of movement are all along the harvester 
forward direction to do the reciprocating movement, so in the all-in-one machine of combine harvester and baler is prone to resonance phenomenon. The second order frequency of the compression device is $3.20 \mathrm{~Hz}$, It is close to the excitation frequency of the fan and the threshing cylinder, and just at the excitation frequency range in the threshing cylinder. In the normal operation of the all-in-one machine of combine harvester and baler, the threshing cylinder and compression device resonance phenomenon will be very obvious.

\section{Conclusions}

1) A parametric model of compression device is established by Solidworks software, and through the finite element simulation software ANSYS-Workbench calculating the first fourth order modal frequency and formation of compression device. Through the modal test were compared with the results of finite element simulation, test results show that the order of the modal frequency and formation is basically consistent with the results of finite element simulation.

2) By comparing the natural frequency and the external excitation frequency of the compression device, The first order frequency is $3.20 \mathrm{~Hz}$, which is in the range of the low order frequency of the road excitation, the cutting table and the vibration sieve, when the whole machine is in normal operation, it is easy to make the vibration sieve with reciprocating motion to produce resonance. The second order frequency is $3.20 \mathrm{~Hz}$, which is in the range of the excitation frequency of the threshing cylinder, this shows that in the normal operation of the all-in-one machine of combine harvester and baler, the threshing cylinder and compression device resonance phenomenon will be very obvious.

3) The research and experiment on vibration characteristics of the compression device of the all-in-one machine of combine harvester and baler is provided, which can provide some theoretical basis for the design optimization of the structure of the following transmission mode and compression device.

\section{Acknowledgements}

This work was financially supported by the Jiangsu science and technology Support Project (BE2014371).

\section{References}

[1] Lujia Han, Qiaojuan Yan. Transactions of The Chinese Society of Agricultural Engineering. 2002,18(3):87-91. (In Chinese)

[2] Xiaohui Yan, Shujun Li and Juntai Yang. Agricultural Engineering.2013,3(4):95-98. (In Chinese)

[3] Xiangpeng Liu, Chuanzhu Sun and Changzun Jiang. Agricultural Mechanization Research.2012,12:76-79. (In Chinese)

[4] Lei Jiang. Farm Machinery,2011(4):119-120 (In Chinese)

[5] Lizhang $\mathrm{Xu}$, Yaoming $\mathrm{Li}$ and Pengpeng Sun. Transactions of The Chinese Society of Agricultural Engineering. 2014,30(8): 49-55. (In Chinese)

[6] Qinglin Li, Cuiying Chen and Chengzhen Ma. Transactions of The Chinese Society of Agricultural Machinery.2005, 36(1) :54-56. (In Chinese)

[7] Hongwei Zhang, Yidu Zhang and Xiping Wang. Transactions of The Chinese Society of Agricultural Engineering.2007,38(3): 35-38. (In Chinese)

[8] Yingyu Wang, Jin Yao and Shanbao Cheng. Mechanical.2003, 30(4): 12 - 14. (In Chinese) 
[9] Longzhe Quan, Jin Tong and Baigong Zeng. Transactions of The Chinese Society of Agricultural Engineering .2011, 27(11): 15 - 20. (In Chinese)

[10] Xiumin Shen, Jindong Diao and Jin Li. Vehicle and Power Technology.2011(2): 42-45. (In Chinese)

[11] Dijiang Wen, Li Zhang and Heng Zhang. Transactions of The Chinese Society of Agricultural Engineering .2005, 21(2): 22-24. (In Chinese)

[12] Zhong Wang, Xiaozhe Wang and Yinnan Yuan. Transactions of The Chinese Society of Agricultural Engineering. 2003,19(2):126-129. (In Chinese)

[13]Yanyan Zuo , Yuying Fang.Transactions of The Chinese Society of Agricultural Engineering.2003,19(4): 107-110. (In Chinese)

[14]Maotao Zhu, Zhigang He. Transactions of The Chinese Society of Agricultural Engineering.2004,(3): 13-15. (In Chinese)

[15] Kroes S, Harris HD. Journal of Agricultural Engineering Research.1995, 62(3): 163-172

[16]Xuexiu Li, Hu Huang and Changhong Liu. Joural of Shanghai university of engineering science.2007(2): 104-108. (In Chinese)

[17]Zhihong Zhang, Jin Tong and Donghui Chen. Transactions of The Chinese Society of Agricultural Engineering. 2012, 28(13): 8-15. (In Chinese)

[18] Rong Guo, Hong Zhou. Journal of Machine Design.2010, 27(8): 18 - 22. (In Chinese)

[19]Qizhi Yu, Danye Chen and Chen Yan. Journal of Donghua University: Natural Science Edition. 2011(4): 493-496. (In Chinese)

[20]Xianhui Wang, Gang Xu and Shoucheng Li. Acta Armamentarii. 2007,28 (8): 903-908. (In Chinese)

[21]Hongxia Yang, Wenchen Tang. Design and Research, 2006, 33(11):14-16. (In Chinese)

[22] Kepeng Zhang, Lin Shao and Jingchun Lü. Automobile Technology, 2012(1): 35 - 39. (In Chinese)

[23]Chunxiang Deng, Jianhua Xiang, Dongcai Tao. Journal of Hunan Agricultural University (Natural Sciences), 2006, 32(2): 199-202. (In Chinese) 